\title{
Research on the electricity-gas coupling system with P2G to absorb surplus hydropower
}

\author{
Wei Wang ${ }^{1}$, Chao Cheng ${ }^{1}$, Xuna Liu ${ }^{1}$, Jieying Liu ${ }^{1}$, Chuan Long ${ }^{1}$, and Wenye Chen ${ }^{2,}$ \\ ${ }^{1}$ State Grid Sichuan Economic Research Institute, Chengdu, China \\ ${ }^{2}$ Chengdu Henghua Electric Power Science and Technology Consulting Co.,Ltd, Chengdu, China
}

\begin{abstract}
With the rapid development of social economy, energy shortage and environmental pollution are becoming more and more serious, and clean energy power generation has become one of the measures to implement the sustainable development strategy. A large number of small and medium-sized hydropower stations in Southwest China have a large amount of surplus water due to light load and channel blockage. In response to this problem, a method of coupling the natural gas system and the power system using $\mathrm{P} 2 \mathrm{G}$ and gas turbines is proposed to improve the absorption capacity of hydropower and reduce the amount of surplus water. In this article, a day-ahead economic dispatch model of electricity-gas coupling system(EGCS) is established with the goal of the lowest operating cost of the whole system, considering the output characteristics of run-off hydropower stations, natural gas system operation constraints, power system AC power flow and other constraints, and solve the model using the interior point method. The analysis of the calculation example shows that compared with the independent system, the EGCS can effectively reduce the amount of surplus water, improve the utilization rate of clean energy, and reduce the operating cost of the system. The rationality and effectiveness of the model are verified.
\end{abstract}

Keyword: Electricity-gas coupling system; Surplus hydropower; Operation optimization.

\section{Introduction}

In recent years, as Chinese economic development has entered a new normal, power demand has slowed down significantly, and environmental pollution and energy shortages have become prominent. The development strategy of the power system is gradually changing, and the proportion of clean energy power generation will gradually expand and become the mainstream form of power generation in the future. Hydropower is a traditional form of clean energy power generation. In 2019, Chinese installed hydropower capacity was 356.4 million kilowatts, accounting for $29.93 \%$ of the total installed capacity. China southwestern region, represented by Sichuan and Yunnan, is rich in water resources. As of November 2019, Sichuan has an installed hydropower capacity of 78.39 million kilowatts, accounting for $78.95 \%$ of the province's installed capacity. Affected by factors such as the mismatch between the rapid development of hydropower and the growth rate of power

\footnotetext{
*Corresponding author: 735018393@qq.com
} 
demand, the flood of incoming water during the flood season, the need for hydropower peaking and abandonment of the power system during the trough period, and the mismatch of the existing transmission channels, the problem of hydropower surplus has gradually increased $^{[1]}$. Therefore, this article considers installing P2G near the hydropower station, and combining the gas turbine to couple the power system and the natural gas system to form an EGCS to increase the absorption capacity of hydropower, which can reduce the amount of surplus water and improve the economic efficiency of system operation.

At present, the research on the EGCS mainly focuses on the optimal dispatch of the system and the planning for P2G. Literature [3] considers resources and technologies such as pumped storage, gas-to-electricity two-way conversion and demand response, constructs a day-ahead optimization model of a EGCS with a high proportion of wind power, and uses interval optimization methods to measure the uncertainty of wind power. Literature [4] proposed a two-tier optimal scheduling model for the power-natural gas integrated energy system that considers the rational use of the wind to be converted from electricity to gas and the optimal operation of the natural gas system. The lower-level model is converted to the upper-level model by KKT conditions and linearized. Solve, its research proves that P2G technology can effectively improve the wind power absorption capacity of the system. Literature [5] introduced the oxy-fuel combustion technology into the electricity-gas-heat integrated energy system, and established a low-carbon economic dispatch model, taking into account the economic and low-carbon operation of the system. Literature [6] constructed a nonlinear model of an integrated energy system including energy hubs and P2G, and optimized the location and capacity of cogeneration units, power-to-gas plants, transmission lines, and natural gas pipelines. The above-mentioned research mainly applies the EGCS to wind power consumption or energy saving and emission reduction, and it rarely involves its research on hydropower consumption.

Therefore, in this article, EGCS model and hydropower output model are established considering the operating characteristics of natural gas system equipment and the operating characteristics and surplus of a run-off hydropower station. Then, a day-ahead economic dispatch model is established with the goal of the lowest total operating cost of the system. Finally, the model is simulated and verified by taking 7-node natural gas system and 7-node power system as examples. The original contribution of this article mainly lies in two points: 1) An output model of runoff hydropower station considering the amount of abandoned water and electricity is established; 2) The effectiveness of EGCS in solving the problem of abandoned water was verified.

\section{Electric-Gas interconnection system model}

\subsection{Natural gas system model}

The branch components of the natural gas network can be divided into pipeline components and compressor components. The characteristics of the piping components only reflect the changes in the pressure at both ends of the branch. The characteristics of compressor components reflect changes in pressure and flow at both ends of the branch.

\subsubsection{Pipeline model}

For the adiabatic gas pipeline $\mathrm{p}$, let its head end be $i$ and its end be $j$, and its steady-state flow equation is as follows: 


$$
\begin{gathered}
F_{\mathrm{p}, i j}=\operatorname{sgn}\left(\pi_{i}, \pi_{j}\right) \cdot \sigma_{i j} \sqrt{\left|\pi_{i}^{2}-\pi_{j}^{2}\right|} \\
\operatorname{sgn}\left(\pi_{i}, \pi_{j}\right)= \begin{cases}1, & \pi_{i} \geq \pi_{j} \\
-1, & \pi_{i} \leq \pi_{j}\end{cases}
\end{gathered}
$$

Where $F_{\mathrm{p}, i j}$ is the pipeline flow between nodes $i j ; \sigma_{i j}$ is the pipeline transmission parameter, which is related to pipeline length, pipe diameter, friction and other related factors; $\pi$ is the node pressure of the natural gas system; $\operatorname{sgn}\left(\pi_{i}, \pi_{j}\right)$ is the symbolic function, which represents the natural gas flow direction, when the pressure at node $i$ is greater than node $\mathrm{j}$, the value is 1 ; otherwise, it is -1 .

\subsubsection{Compressor model}

The transmission of natural gas depends on the pressure difference, so in order to increase the transmission capacity of the gas network, compressors need to be configured in the network. The characteristic equation of the compressor is related to the flow through the compressor and the boost ratio.

$$
\begin{gathered}
Q_{\mathrm{c}, i j}=\delta_{i j} F_{\mathrm{c}, i j}\left[\left(\pi_{j} / \pi_{i}\right)^{\alpha}-1\right] \\
\tau_{\mathrm{c}, i j}=\beta_{1}+\beta_{2} Q_{\mathrm{c}, i j}+\beta_{3} Q_{\mathrm{c}, i j}^{2}
\end{gathered}
$$

Where $Q_{\mathrm{c}, i j}$ is the energy consumed by the compressor working; $\delta_{i j}$ is the characteristic constant of the compressor unit, which is related to the calorific value of natural gas, compressor efficiency, temperature, etc.; $\alpha$ is a constant related to the compression factor and the calorific value of natural gas; $\tau_{\mathrm{c}, i j}$ is the equivalent natural gas flow consumed; $\beta$ is the energy conversion factor.

\subsubsection{Node flow balance equation}

Neglecting the transmission loss of natural gas pipeline, the node flow balance equation of natural gas system is:

$$
\mathbf{F}_{\mathrm{s}}+\mathbf{F}_{\mathrm{P} 2 \mathrm{G}}-\mathbf{A} \cdot \mathbf{F}_{\mathrm{p}}-\tau_{\mathrm{c}}-\mathbf{F}_{\mathrm{L}}=\mathbf{0}
$$

Where $\mathbf{F}_{\mathbf{s}}$ is the gas source output flow matrix; $\mathbf{F}_{\mathbf{P 2 G}}$ is the $\mathrm{P} 2 \mathrm{G}$ output flow matrix; $\mathbf{A}$ is the node correlation matrix; $\mathbf{F}_{\mathbf{p}}$ is the natural gas pipeline flow matrix (the pipeline containing the compressor is subject to the compressor outlet flow); $\boldsymbol{\tau}$ is the flow loss matrix at the compressor inlet; $\mathbf{F}_{\mathbf{L}}$ is the natural gas load matrix. 


\subsection{Power system model}

\subsubsection{Output model of hydropower station}

The output of a hydropower station is related to the upstream and downstream water level (head) and the water flow used. The surplus water is represented by electricity. It assumes that the surplus water power is the difference between the maximum theoretical output of the turbine and the actual output. The mathematical model is as follows:

$$
\begin{gathered}
P_{\text {hydro }}^{t}=K \cdot Q^{t} \cdot H \\
P_{\text {abandon }}^{t}=P_{\text {hydro }}^{t, \text {max}}-P_{\text {hydro }}^{t} \\
P_{\text {hydro }}^{t, \text { max }}=\min \left\{P_{\text {hydro }}^{\max }, K Q_{\text {water }}^{t} H\right\} \\
Q^{\min } \leq Q^{t} \leq \min \left\{Q^{\max }, Q_{\text {water }}\right\} \\
P_{\text {hydro }}^{\min } \leq P_{\text {hydro }}^{t} \leq P_{\text {hydro }}^{\max }
\end{gathered}
$$

Where $P_{\text {hydro }}^{t}$ is the hydropower during the $t$ period; $P_{\text {hydro }}^{\max } / P_{\text {hydro }}^{\min }$ is the upper and lower limits of hydropower; $K$ is the output coefficient of the hydropower station, usually 6.5 8.0 for small and medium-sized hydropower stations; $H$ is the working head of the hydropower station, and the rated head is used in this article; $Q^{\max } / Q^{\min }$ is the $\max / \mathrm{min}$ used flow of the turbine; $Q_{\text {water }}^{t}$ is the natural inflow of water in the basin where the hydropower station is located in period $t ; P_{\text {abandon }}^{t}$ is the surplus water power in period $t$.

\subsubsection{Power flow equation of power system}

This article uses the AC power flow model of the power system.

\subsection{Coupling facility model}

Coupling facility includes $\mathrm{P} 2 \mathrm{G}$ and gas turbine.

$$
\begin{aligned}
& F_{\mathrm{P} 2 \mathrm{G}}^{t}=\frac{\eta_{\mathrm{P} 2 \mathrm{G}} \cdot P_{\mathrm{P} 2 \mathrm{G}}^{t}}{G H V} \\
& P_{\mathrm{GT}}^{t}=\eta_{\mathrm{GT}} \cdot F_{\mathrm{GT}}^{t} \cdot G H V
\end{aligned}
$$

Where $F_{\mathrm{P} 2 \mathrm{G}}^{t}$ is the natural gas flow rate output by the $\mathrm{P} 2 \mathrm{G} ; \eta_{\mathrm{P} 2 \mathrm{G}}$ is the efficiency coefficient of the $\mathrm{P} 2 \mathrm{G} ; P_{\mathrm{P} 2 \mathrm{G}}^{t}$ is the power consumption of the $\mathrm{P} 2 \mathrm{G} ; G H V$ is the calorific value of the natural gas, which is a constant; $P_{\mathrm{GT}}^{t}$ is output electric power of gas turbine; $\eta_{\mathrm{GT}}$ is efficiency coefficient of gas turbine; $F_{\mathrm{GT}}^{t}$ is input natural gas flow of gas turbine. 


\section{Day-ahead economic dispatch model}

\subsection{Objective function}

A day-ahead economic dispatch model for the electricity-gas interconnected system is established, taking into account the cost of abandoning water of hydropower stations, the cost of generating electricity from conventional units, and the cost of gas production, which aims at the lowest system operating cost. The objective function is:

$$
\begin{aligned}
C & =C_{\text {water }}+C_{\text {gen }}+C_{\text {gas }} \\
& =\sum_{t}^{24} P_{\text {abandon }}^{t} \cdot p_{\text {water }}+\sum_{t}^{24} P_{\text {gen }}^{t} \cdot p_{\text {gen }}+\sum_{t}^{24} F_{\text {gas }}^{t} \cdot p_{\text {gas }}
\end{aligned}
$$

Where $p_{\text {water }}, p_{\text {gas }}, p_{\text {gen }}$ are the cost of surplus water of the hydropower station, the cost of gas production, and the cost of power generation of conventional units; $P_{\text {gen }}^{t}$ is the output of conventional units and the gas production of natural gas systems.

\subsection{Constraints}

The constraints of the model include natural gas system constraints, power system constraints and technical constraints of coupling facilities. Natural gas system constraints include gas source output constraints, node pressure constraints, and compressor boost ratio constraints. Power system constraints include conventional unit output constraints, node voltage constraints and branch power flow constraints. Coupled facilities constraints include gas turbines and P2G output constraints. The detailed content can be found in [10$15]$.

\section{Solution method}

The above model is essentially a non-linear programming problem. The interior point method is often used as the preferred algorithm for solving nonlinear programming problems because of its high efficiency and accuracy. This article uses MATLAB to call the IPOPT solver in the OPTI toolbox to solve the model. The principle of the internal point method can be referred to [15].

\section{Example analysis}

\subsection{Calculation example settings}

This article uses 7-node power system and 7-node natural gas system for simulation, and the system structure is shown in Figure 1. For the selection of the maximum power generation of a hydropower station, this article refers to the water flow data of a certain river basin and expands it proportionally to determine the maximum power generation per hour of the hydropower station. In order to highlight the advantages of the EGCS, this article sets up two scenarios for comparison: Scene 1: Power system and natural gas system operate independently; Scene 2: Power system and natural gas system form a bidirectional flow of energy through $\mathrm{P} 2 \mathrm{G}$ and gas turbines. 


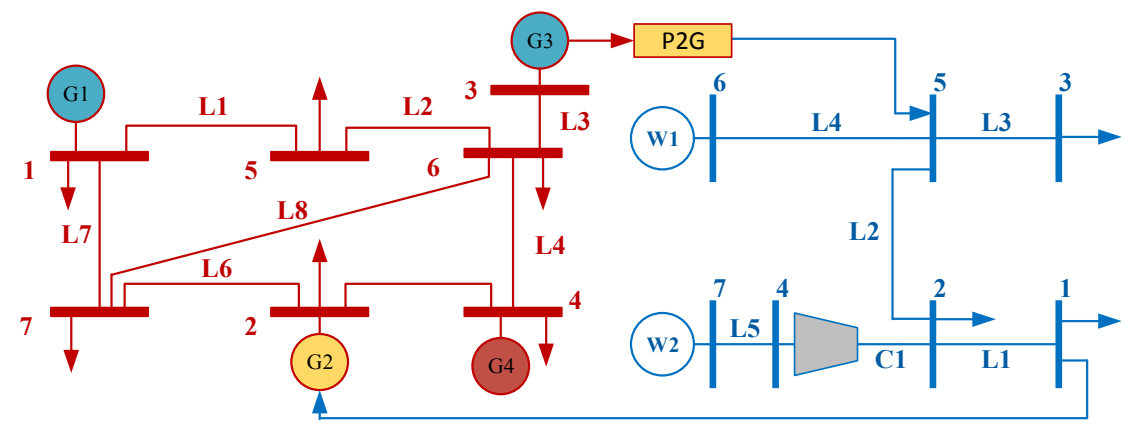

Fig. 1. Schematic diagram of EGCS.

\subsection{Result analysis}

The output of the hydropower station and the amount of surplus water are shown in Figure 2.

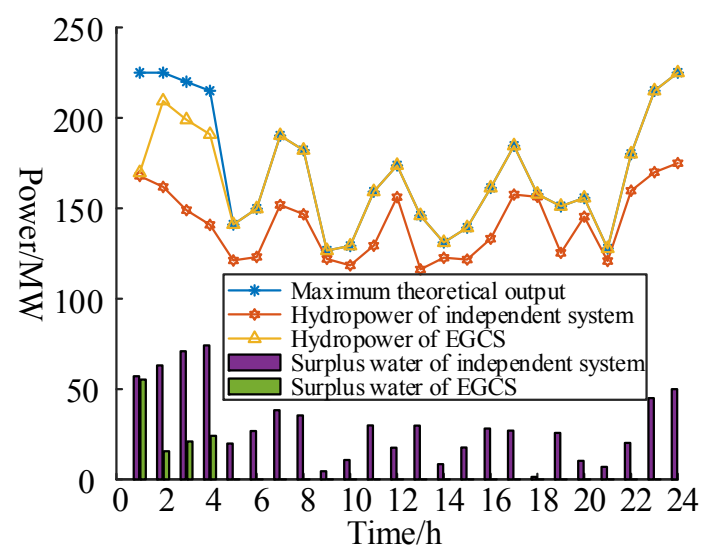

Fig. 2. Operation of hydropower.

It can be seen that when the power system is operating independently, there is still a certain gap between the planned output value of the hydropower station and the maximum theoretical output value, due to the low load level and the power limitation of the tie line, so a large amount of water will be discarded. After equipping 50MW of P2G, the original two independent systems are coupled into an EGCS. The output of the hydropower station can not only be absorbed by the electric load, but also can be converted into natural gas by P2G. In the period 5-24, it can be seen that the output of the hydropower station has reached the theoretical maximum and no surplus water. In the period 1-4, due to the P2G capacity limitation and the water flow is sufficient at this time, there will still be a small amount of surplus water.

The operating results of the EGCS and the independent system are shown in Table 1. The table shows that the EGCS can reduce power generation costs by $41.12 \times 10^{4}$ yuan, and reduce surplus water costs by $6.04 \times 10^{4}$ yuan, which reduces operating costs by $24.95 \times 10^{4}$ yuan in total. In addition, it also reduces the surplus water power $603.76 \mathrm{MWh}$ and the power loss $9.31 \mathrm{MWh}$. From the operating results of the two scenarios, we can clearly see that the EGCS significantly reduces operating costs and surplus water, and power loss. This is due to the intervention of natural gas system. On the one hand, it provides more ways for power transmission of the power system, improves the power flow distribution of the 
system, and then reduces the network loss. On the other hand, it provides a way to absorb the surplus water and electricity resources.

Table 1. Operation results of EGCS and independent systems.

\begin{tabular}{lcc}
\hline & Independent systems & EGCS \\
\hline Cost of generating electric/yuan & $109.22 \times 10^{4}$ & $68.10 \times 10^{4}$ \\
Cost of generating gas/ yuan & $186.59 \times 10^{4}$ & $208.80 \times 10^{4}$ \\
Cost of surplus water / yuan & $7.20 \times 10^{4}$ & $1.16 \times 10^{4}$ \\
Cost of operation / yuan & $303.00 \times 10^{4}$ & $278.05 \times 10^{4}$ \\
Power of surplus water /MWh & 719.74 & 116.00 \\
Power loss /MWh & 67.09 & 57.78 \\
\hline
\end{tabular}

The power output of the power system and natural gas system equipment in scenario 2 is shown in Figure 3 and Figure 4. It can be seen from Figure 3 that in the 24-7 period, the output of conventional units and gas turbines is small. It mainly due to the fact that this period is night time, and the electric load level is low, and the water flow is relatively abundant, the theoretical power generation capacity of the hydropower station is high, and the system is more inclined to use low-cost hydropower for power output. At this time, the output of P2G is at a relatively high level. But limited by its own capacity, a small amount of surplus water is still produced. This part of the surplus water is mainly due to insufficient load level, which cannot completely absorb natural water. Observing the output curve of the gas turbine and the conventional unit, it can be seen that the gas turbine starts to output earlier than the conventional unit. Mainly because that generate electric by gas turbines is cheaper than the conventional units. Therefore, in the dispatch plan, it is more inclined to use gas turbine output first, and then supplement it with conventional units when the load demand is still not met.
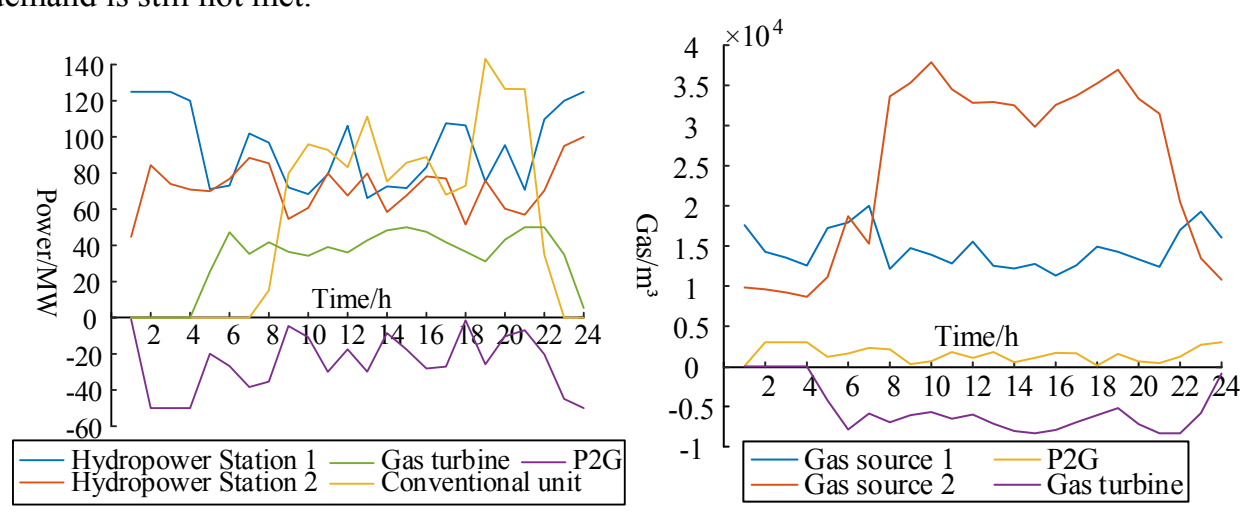

Fig. 3. Output of power system equipment. Fig. 4. Output of natural gas system equipment.

It can be seen from Figure 4 that since the natural gas load is at a relatively high level during the period 6-22, the gas source 1 is almost at full power, and the insufficient part of the load is supplemented by the gas source 2 . Gas turbine power generation consumes part of the natural gas, which can be regarded as a type of load of the natural gas system. The $\mathrm{P} 2 \mathrm{G}$ is working all the time, providing a small amount of natural gas, which can be regarded as a small gas source for the natural gas system.

\section{Conclusion}

In this article, a hydropower model considering the surplus water is established, combined with the operating characteristics of a run-off hydropower station, Then, a nonlinear model of the EGCS is established, considering the natural gas system operation constraints and the 
power system AC power flow constraints. Based on the research content of this article, the following conclusions can be drawn:

1) P2G uses the surplus water resources of hydropower stations to convert surplus water into natural gas for consumption, which significantly reduces the amount of surplus water and improves the use of clean energy. The natural gas produced by P2G can meet part of the natural gas load demand, reduce the cost of gas production, and improve the operating economy of the system. In this example, EGCS reduced the amount of water and electricity abandoned by $83.88 \%$ and reduced operating costs by $8 \%$.

2) The gas turbine and $\mathrm{P} 2 \mathrm{G}$ realize the two-way coupling of energy between the power system and the natural gas system, which improves the flexibility of system operation. At the same time, the coupling system is more conducive to the power flow distribution of the power system and significantly reduces the power loss. In this example, the line loss of EGCS was reduced by $13.88 \%$.

\section{Acknowledgments}

This work was supported in part by the State Grid Sichuan Economic Research Institute(item number: B7199721B021).

\section{References}

1. BO Rui, LUO Yangtao, LI liang. Study on safeguard measures of Sichuan hydropower consumption[J]. Design of Hydroelectric Power Station, 2019,35(4):97-102.

2. LIU Weijia, WEN fushuan, XUE Yusheng, ZHAO Junhua, DONG Zhaoyang, ZHENG $\mathrm{Yu}$. Cost Characteristics and Economic Analysis of Power-to-gas Technology[J]. Automation of Electric Power Systems, 2016,40(24):1-11.

3. SU Yongxin, NIE Weiqi, TAN Mao. Day-ahead Interval Optimization of Integrated Energy System Considering Wind Power Integration and Gas-Electricity Transformation[J]. Automation of Electric Power Systems, 2019,43(17):63-74.

4. ZHANG Rufeng, JIANG Tao, LI Guoqing, CHEN Houhe, LI Xue, NING Ruoxi. Bilevel Optimization Dispatch of Integrated Electricity-Natural Gas System Considering P2G for Wind Power Accommodation[J]. Proceedings of the CSEE, 2018,38(19):5668$5678,5924$.

5. CUI Yang, ZENG Peng, ZHONG Wuzhi, WANG Zheng, ZHANG Peng, ZHAO Yuting. Low-carbon Economic Dispatch of Electro-gas-thermal Integrated Energy System Based on Oxy-combustion Technology[J]. Proceedings of the CSEE, 2021,41(2):592-608.

6. HUANG Guori, LIU Weijia, WEN Fushuan, DONG Zhaoyang, ZHENG Yu, ZHANG Rui. Collaborative Planning of Integrated Electricity and Natural Gas Energy Systems with Power-to-Gas Stations[J]. Electric Power Construction, 2016, 37(9): 1-13.

7. XU Zhiheng. Optimal Dispatching of Integrated Natural gas and Electricity System and Configuration of P2G Facilities[D]. South China University of Technology, 2018.

8. ZHANG Li, YANG Jiang, JIAN Xuehui, ZHANG Feng, HAN Xueshan. Unit Commitment with Energy Storage Considering Operation Flexibility at Sub-hourly Time-scales[J]. Automation of Electric Power Systems, 2018, 42(16): 21-31, 56.

9. XU Zhiheng, ZHANG Yongjun, CHEN Zexing, LIN Xiaoming, CHEN boda. Bi-level Optimal Capacity Configuration for Power to Gas Facilities Considering Operation 
Strategy and Investmen Subject Benefit[J]. Automation of Electric Power Systems, 2018, 42(13): 76-84.

10. TAO Xiaolong. The Study on the Calculation Model of Abandon Hydropower[D]. North China Electric Power University, 2014.

11. YANG Zijuan, GAO Ciwei, ZHAO Ming. Review of Coupled System Between Power and Natural Gas Network[J]. Automation of Electric Power Systems, 2018, 42(16): 21$31,56$.

12. XU Zhiheng, ZHANG Yongjun, CHEN Zexing, LIN Xiaoming, CHEN Boda. Bi-level Optimal Capacity Configuration for Power to Gas Facilities Considering Operation Strategy and Investment Subject Benefit[J]. Automation of Electric Power Systems, 2018, 42(13): 76-84.

13. WEI Zhinong, ZHANG Side, SUN Guoqiang, ZANG Haixiang, CHEN Sheng, CHEN Shuang. Power-to-gas Considered Peak Load Shifting Research for Integrated Electricity and Natural-gas Energy Systems[J]. Proceedings of the CSEE, 2017, 37(16): 4601-4609+4885.

14. Gong Xiaoqin, WANG Jin, WANG Long, ZHANG Han, QIAN Jiahui, DENG Minghui. Low-carbon economic operation for integrated electricity and natural-gas energy system with power-to-gas[J]. Journal of electric power science and technology, 2020, 35(02): 76-83.

15. ZHENG Zhan. Models and Algorithms Research of Optimization Operation for Interdependent Electricity-Natural Gas Network in Integrated Energy System[D]. South China University of Technology, 2018. 